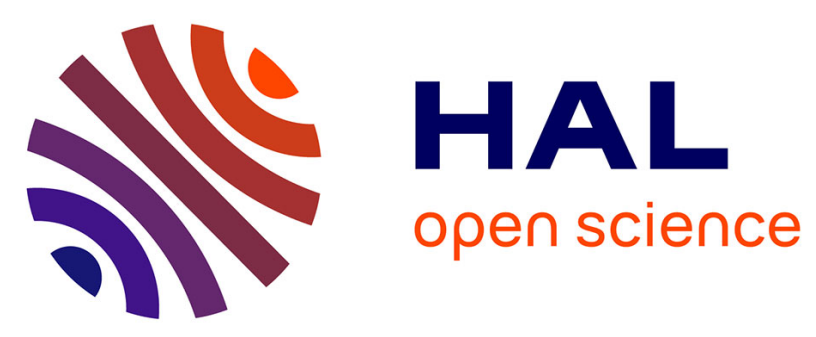

\title{
The role of stearic acid in ascorbic acid protection from degradation: a heterogeneous system for homogeneous thermodynamic data
}

Yohann Corvis, Marie-Claude Menet, Philippe Négrier, Mathieu Lazerges, Philippe Espeau

\section{To cite this version:}

Yohann Corvis, Marie-Claude Menet, Philippe Négrier, Mathieu Lazerges, Philippe Espeau. The role of stearic acid in ascorbic acid protection from degradation: a heterogeneous system for homogeneous thermodynamic data. New Journal of Chemistry, 2013, 37 (3), pp.761-768. 10.1039/C2NJ40933J . hal-00798549

\section{HAL Id: hal-00798549 \\ https://hal.science/hal-00798549}

Submitted on 8 Jan 2018

HAL is a multi-disciplinary open access archive for the deposit and dissemination of scientific research documents, whether they are published or not. The documents may come from teaching and research institutions in France or abroad, or from public or private research centers.
L'archive ouverte pluridisciplinaire HAL, est destinée au dépôt et à la diffusion de documents scientifiques de niveau recherche, publiés ou non, émanant des établissements d'enseignement et de recherche français ou étrangers, des laboratoires publics ou privés.

\section{(ㅇ)(1) $\$$}

Distributed under a Creative Commons Attribution - NonCommercial - NoDerivatives 44.0 


\title{
The role of stearic acid in ascorbic acid protection from degradation: a heterogeneous system for homogeneous thermodynamic data
}

\author{
Yohann Corvis, ${ }^{a}$ Marie-Claude Menet, ${ }^{b}$ Philippe Négrier, ${ }^{c d}$ Mathieu Lazerges ${ }^{\mathrm{a}}$ and \\ Philippe Espeau*a
}

\begin{abstract}
A heterogeneous system between vitamin C and stearic acid was characterized by thermal and crystallographic analyses. The results showed that such a system prevents vitamin $C$ from thermal decomposition. The evidence was provided by implementing a new protocol associating chromatic assays and thermal analyses in order to quantify the percentage of non degraded vitamin $C$. The results collected with the vitamin $C$ stearic acid mixtures allowed deducing coherent interpretation of the results obtained with pure vitamin $C$ at different heating scan rates. Vitamin $C$ mainly degrades upon melting but also in the solid state for temperature close to the melting point when the heating rates are very low. Under these conditions, the temperature determined at the onset of the DSC graphs cannot be associated with the melting temperature but with a fusion degradation phenomenon. At higher scan rates, the onset as well as the endothermic value of the signal increase to reach plateau values. These values have been identified as the temperature and enthalpy values of melting of vitamin $\mathrm{C}$ according to the results obtained from the heterogeneous system.
\end{abstract}

\section{Introduction}

Vitamin C (VC), the levorotatory enantiomer of ascorbic acid is one of the most widely used ingredients for cosmetic applications. ${ }^{1,2}$ VC can potentially benefit the skin in two important ways. Firstly, it is essential to synthesize collagen, a key structural protein of the skin. Secondly, as an antioxidant, VC can help reduce skin damage caused by free radicals. Thus, when vitamin $\mathrm{C}$ is properly delivered into skin cells, there is a good chance to reduce wrinkles and improve skin texture. However, this pharmaceutical ingredient is relatively unstable, in particular under thermal ${ }^{3}$ and wet conditions. Previous investigations performed upon heating of vitamin $\mathrm{C}$ at various scan rates $^{4}$ have shown that the onset temperature of the "apparent" melting peak increases with the heating rate, which could indicate a fusion-degradation process, as previously

\footnotetext{
${ }^{a}$ Laboratoire Physico Chimie Industrielle du Médicament, EA 4066, Université Paris Descartes, Sorbonne Paris Cité, Faculté des Sciences Pharmaceutiques et Biologiques, 4 Avenue de l'Observatoire, 75006 Paris, France. E mail: philippe.espeau@parisdescartes.fr; Tel: +33153739676

${ }^{b}$ Université Paris Descartes, Sorbonne Paris Cité, Faculté des Sciences Pharmaceutiques et Biologiques, 4 Avenue de l'Observatoire, 75006 Paris, France

${ }^{c}$ Université Bordeaux, LOMA, UMR 5798, F 33400 Talence, France

${ }^{d}$ CNRS, LOMA, UMR 5798, F 33400 Talence, France
}

reported for spironolactone. ${ }^{5}$ But the latter experiments were performed with heating rates no higher than $10{ }^{\circ} \mathrm{C} \min ^{-1}$. However, one cannot speculate that a very high heating rate would avoid chemical degradation during melting. Nevertheless, discrepancies in the data corresponding to VC melting can be noticed in the literature. As a matter of fact, the occurrence of degradation during melting could explain these incoherent data. The aim of the present work is to propose a new approach by combining (i) pre-formulation of a suitable excipient-VC association, the excipient playing the role of a thermal protecting agent for ascorbic acid and, (ii) an analytical-thermal method association to study VC degradation under different experimental conditions. Besides, high-performance liquid chromatography (HPLC) and thermal analyses - differential scanning calorimetry (DSC), and thermo-gravimetric analysis (TGA) were associated to follow VC degradation upon heating without ambiguities. On the one hand, VC chemical protection from degradation was apprehended, and, on the other hand, the analytical-thermal method association was validated by comparing the results obtained under the same conditions, with or without the use of the excipient. As a matter of fact, stearic acid (SA) has retained our attention since the VC-SA binary system is heterogeneous. The particularity of such a system is that each compound of the system retains its own physico-chemical properties. 
Interestingly, stearic acid is often used as an emollient in cosmetics, ${ }^{6}$ but also as a lubricant in the pharmaceutical industry. $^{7,8}$

\section{Experimental section}

\section{Chemicals}

L-Ascorbic acid (vitamin C) was purchased from Acros organics (99\% purity), stearic acid from Alfa Aesar (98\% purity) and riboflavin from Sigma ( $98 \%(w / w)$ purity). The products were used as received.

\section{Sample preparation}

The VC-AS mixtures were obtained by mechanically mixing both pure components in a mortar at room temperature.

\section{Methods}

The differential scanning calorimetry and thermo-gravimetric analysis experiments were performed using an 822e thermal analyzer and a TGA 850 from Mettler-Toledo (Switzerland). Indium was used for temperature and enthalpy calibration of the DSC device. For all the experiments, an empty aluminum pan was used as a reference. The melting temperatures were determined at the onset of the corresponding endotherms. The multiple thermocouple sensor technology of the device allows a tau lag calibration, ${ }^{9}$ i.e. eliminates the heating rate and heat flux dependence on the measured data. The DSC and TGA experiments were carried out at different scan rates from 1 to $90{ }^{\circ} \mathrm{C} \mathrm{min}^{-1}$, under a constant nitrogen flow of $60 \mathrm{~mL} \mathrm{~min}^{-1}$. Sample masses around $10 \mathrm{mg}$ were used for the experiments.

$\mathrm{X}$-ray powder diffraction profiles were recorded using a highresolution INEL diffractometer equipped with a CPS (Curve Position angular Sensitive detector) 120 position-sensitive multidetector (Debye-Scherrer geometry, transmission mode, $\mathrm{Cu} \mathrm{K} \alpha 1$ radiation $(\lambda=1.5418 \AA))$.

The thermal degradation of VC under isothermal conditions was analyzed by high performance liquid chromatography as follows: a given mass of VC (about $10 \mathrm{mg}$ ) was placed into a DSC pan. The sample was then heated at a temperature close to the melting temperature, i.e. $195{ }^{\circ} \mathrm{C}$, at different times, ranging from 1 to $30 \mathrm{~min}$. Once the heating time was reached, the sample was quenched at $0{ }^{\circ} \mathrm{C}$ to stop the degradation process. The content of the pan was dissolved in $50 \mathrm{~mL}$ of aqueous solution of riboflavin at $4 \mathrm{mg} \mathrm{L}^{-1}$. The solution obtained was then filtered using a Büchner funnel in order to eliminate SA as it is not soluble in water.

The HPLC method was used to detect the degradation products occurring during heating and to determine the ascorbic acid concentration in solution. The products were separated on a Kinetec column $(2.6 \mu \mathrm{m}, 5 \mathrm{~cm}, 2.1 \mathrm{~mm}$ internal diameter, Phenomenex, Le Pecq, France), where the stationary phase was an unmodified silica-type HILIC (Hydrophilic Interaction Chromatography). The column was connected to a conventional Shimadzu high-performance liquid chromatography system (Shimadzu France, Champs sur Marne, France). This instrument included a Shimadzu solvent delivery system
LC-10AS ${ }^{\circledR}$ together with a Shimadzu SPDE-10A ${ }^{\circledR}$ UV-visible detection system set at $260 \mathrm{~nm}$. The mobile phase was a mixture of $96 \%(\mathrm{v} / \mathrm{v})$ acetonitrile of HPLC grade $(99.93 \%(\mathrm{w} / \mathrm{w})$, Sigma Aldrich, Saint Quentin Fallavier, France) and 4\% (v/v) aqueous solution of ammonium formate (Sigma, Saint Quentin Fallavier, France) at $0.1 \mathrm{~mol} \mathrm{~L}^{-1}$ and at $\mathrm{pH}$ 3.5. The flow-rate was set at $0.2 \mathrm{~mL} \mathrm{~min}^{-1}$. Under such conditions, the retention times of riboflavin and ascorbic acid were $5 \mathrm{~min}$ (CV 0.8\%) and $7.7 \mathrm{~min}$ (CV 2\%), respectively. The raw data were acquired by Borwin ${ }^{\circledR}$ program (JMBS Développements, Grenoble, France). As regards the $\log P_{\text {oct/water values, they were calculated by using MarvinSketch }}$ 5.7.0 (ChemAxon, Budapest, Hungary).

The calibration curve was performed with different VC masses, named calibrators, and covered a range from 5 to $20 \mathrm{mg}$. Each mass was dissolved in $50 \mathrm{~mL}$ of riboflavin solution and filtered before analysis. There were linear relationships between the peak area ratio of VC to internal standard and the mass of calibrators over the mass range investigated.

\section{Results and discussion}

Prior to this study, excipients such as lactose, L-menthol, DL-camphor, and vanillin were tested to find the most convenient excipient-vitamin $\mathrm{C}$ association. As a result, stearic acid has been selected as a suitable candidate since it forms a heterogeneous system once mixed to VC. Moreover, as shown below, it plays the role of a protective agent for VC.

\section{Thermal stability of the pure compounds}

When stearic acid is heated, up to its melting point, at different scan rates from 1 to $60{ }^{\circ} \mathrm{C} \mathrm{min}^{-1}$, the resulting DSC thermograms do not undergo any significant modifications (Fig. 1A).

In contrast, when vitamin $\mathrm{C}$ is heated under the same conditions, the thermograms clearly exhibit degradation traces at low heating rates as shown in Fig. 1B. At low scan rates, just before and after the melting peak, a background noise appears and increases while the scan rate decreases. This argues for VC instability during the thermal process.

Regarding the melting temperature, no change in the temperature of fusion was observed for SA on the overall range of scan rates (Fig. 1C), which goes along with the thermal stability of the compound during melting. An average temperature of fusion was then determined: $T_{\text {fus }}=69.4 \pm 0.3{ }^{\circ} \mathrm{C}$.

In contrast, for $\mathrm{VC}$, the onset of the "apparent" melting temperature increases with the scan rate (Fig. 1D), and reaches a plateau, for $v \geq 30{ }^{\circ} \mathrm{C} \mathrm{min}^{-1}$, with a value equal to $193.7 \pm 0.5^{\circ} \mathrm{C}$. The incidence of the heating rate on VC instability during melting has previously been reported. ${ }^{4}$ However, the authors carried out DSC experiments only with scan rates from 2 to $10{ }^{\circ} \mathrm{C} \mathrm{min}^{-1}$, which seems to be insufficient regarding the present study. Indeed, at high scan rates, the melting process probably prevails on the degradation process and the plateau value obtained in Fig. 1D may correspond to the true value of the melting temperature of $\mathrm{VC}$ since the value agrees with the literature data. At low scan rates $\left(v \leq 2{ }^{\circ} \mathrm{C} \min ^{-1}\right)$, 
A

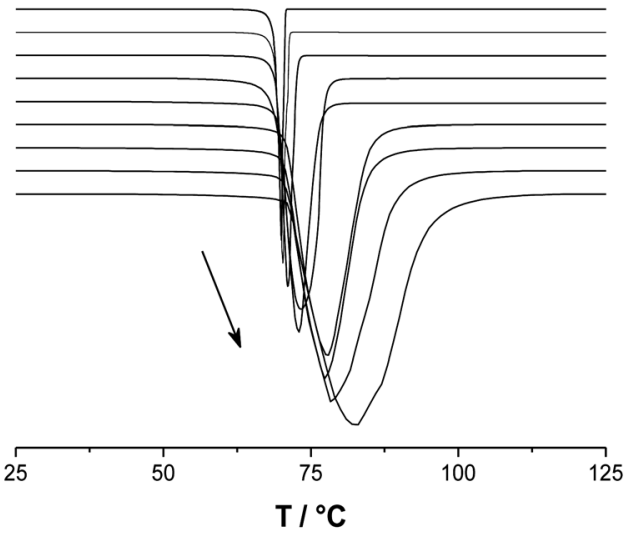

$\mathrm{C}$

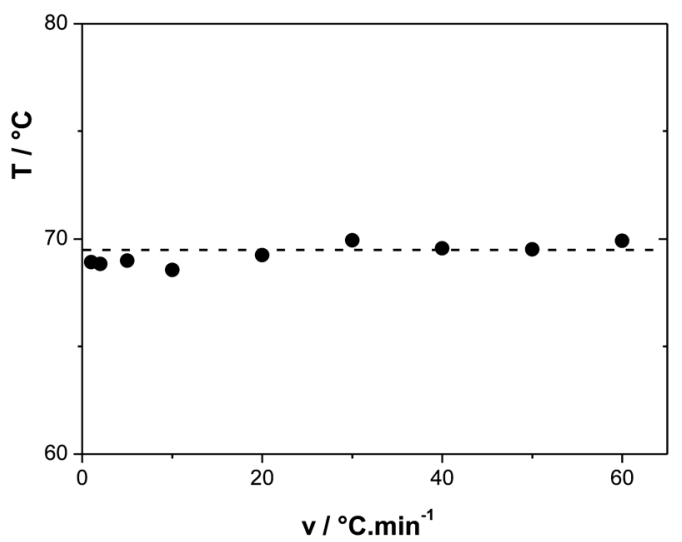

$\mathrm{B}$

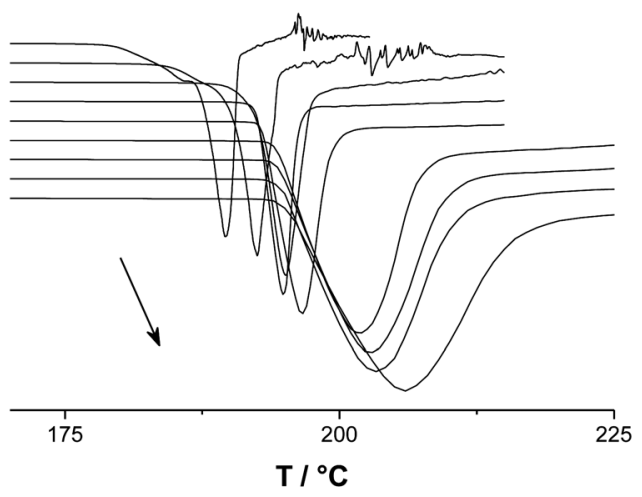

$\mathrm{D}$

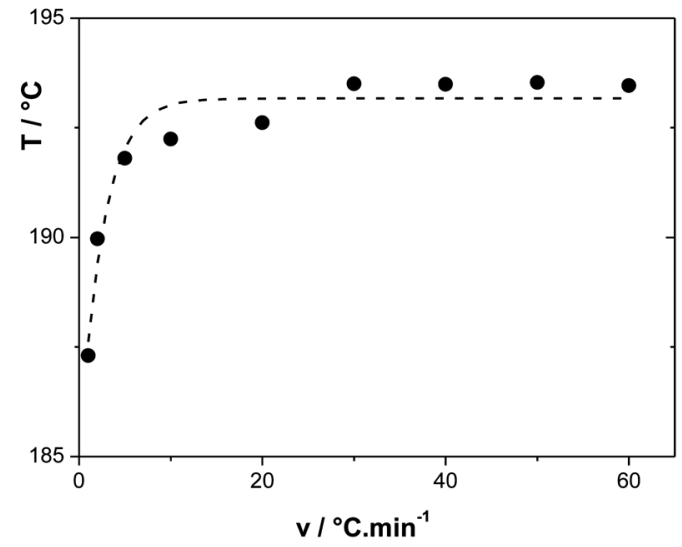

Fig. 1 DSC thermograms and melting temperatures as a function of the heating rate for stearic acid ( $A$ and $C)$, and vitamin $C(B$ and $D)$. The arrows indicate the direction of the increase of the scan rate.

the degradation mainly appears just before melting, as suggested by the shoulder visible before the broad endothermic signal (Fig. 1b). One may therefore safely conclude that, in the solid state, at temperatures relatively far from the melting point, no degradation occurs or, if it does, it can be neglected. This assumption was verified by $\mathrm{X}$-ray diffraction experiments carried out at different temperatures from ambient conditions to $100{ }^{\circ} \mathrm{C}$ (Fig. 2). It clearly appears that no degradation takes place during heating since no supplementary peaks are visible. This allows us to assert the thermal stability of VC in the solid state.

As far as the enthalpy of fusion is concerned, no variation of the values was found for pure SA with the scan rate (Fig. 3A), allowing us to determine an average value, $\Delta_{\text {fus }} H=$ $61.3 \pm 1.3 \mathrm{~kJ} \mathrm{~mol}^{-1}$. However, for pure $\mathrm{VC}$, one cannot assert that the endothermic signal associated heat corresponds to the melting enthalpy since its value significantly increases with the scan rate to reach a plateau value at $45.5 \pm 0.7 \mathrm{~kJ} \mathrm{~mol}^{-1}$ (Fig. 3B). The latter value is of the same magnitude as the VC melting data obtained by $\operatorname{Tan}^{10}$ and Park $^{11}$ (Table 1). The influence of the scan rate on the endothermic signal heat measured confirms that VC does degrade upon melting. Consequently, one cannot dissociate the melting of vitamin $\mathrm{C}$ from the degradation process as Tan suggested ten years ago. ${ }^{10}$ To confirm the latter hypothesis, the DSC experiments were

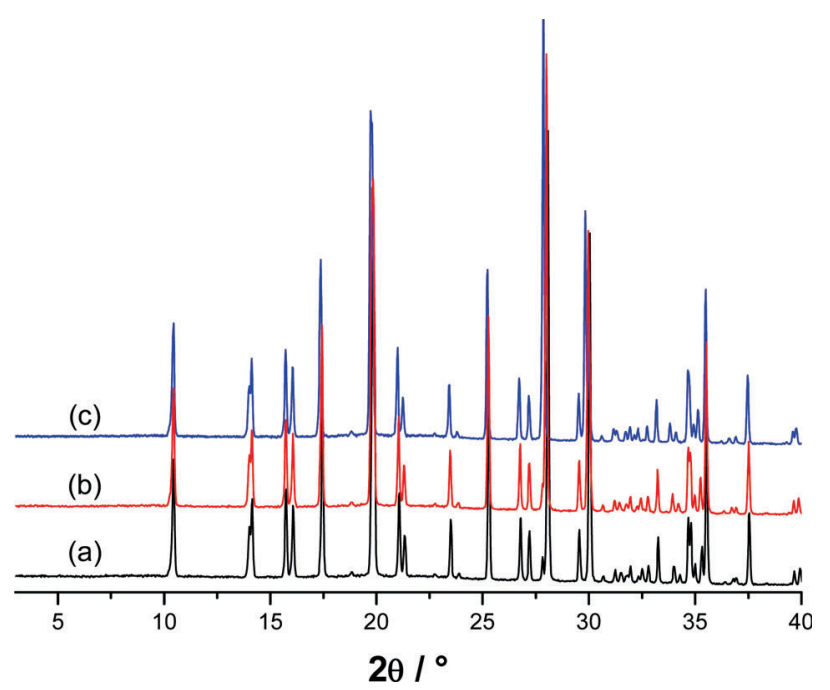

Fig. 2 Powder $R X$ diffraction patterns of pure vitamin $C$ as a function of temperature: (a) 22 , (b) 50 , and (c) $100{ }^{\circ} \mathrm{C}$.

reproduced under the same conditions as in ref. 10, using hermetically sealed and half-opened pans (curves A in Fig. 4).

From the analysis of Fig. 4, it may be assumed that the endothermic signal observed around $210{ }^{\circ} \mathrm{C}$ in the 

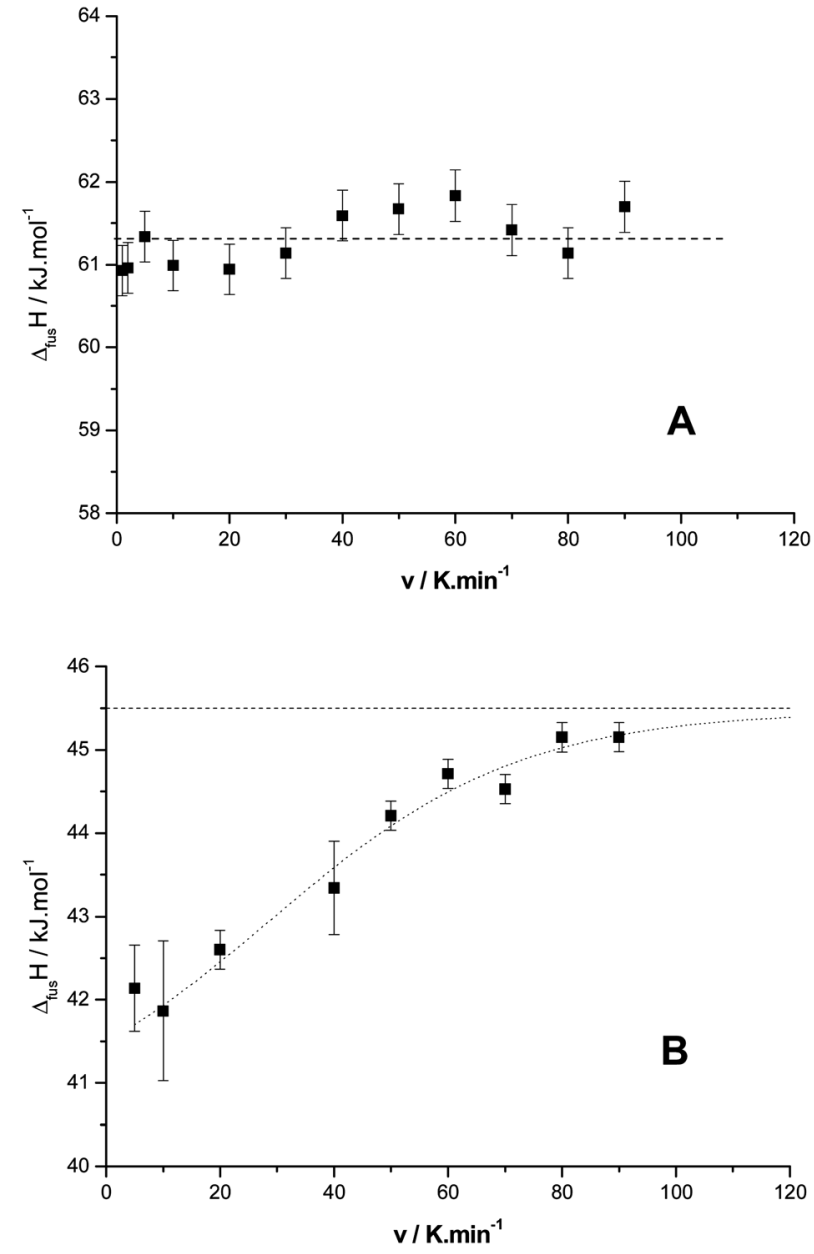

Fig. 3 Evolution of the endothermic heat as a function of the heating scan rate for stearic acid (A), and vitamin C (B).

Table 1 Temperature and enthalpy of melting for vitamin $C$ and for stearic acid

\begin{tabular}{lllll}
\hline & Vitamin C & References & Stearic acid & References \\
\hline$T_{\text {fus }}\left({ }^{\circ} \mathrm{C}\right)$ & $193.7 \pm 0.5^{a}$ & This work & $69.4 \pm 0.3^{a}$ & This work \\
& $192.2 \pm 0.5^{b}$ & This work & $69.2 \pm 0.7^{b}$ & This work \\
191.2 & 4 & $69.5 \pm 0.1$ & 16 \\
193.5 & 10 & 69.6 & 17 \\
193.57 & 11 & $69.4 \pm 0.3$ & 18 \\
197.0 & 12 & & \\
191 & 13 & & \\
190.8 & 14 & & \\
& 190.4 & 15 & $61.3 \pm 1.3^{a}$ & This work \\
& n.d. & & & \\
& $45.3 \pm 0.9^{b}$ & This work & $61.1 \pm 0.4^{b}$ & This work \\
& 45.6 & 10 & $61.2 \pm 0.2$ & 16 \\
& & & 61.3 & 17 \\
& 47.1 & 11 & $63.2 \pm 1.4$ & 18 \\
& 37.0 & 12 & & \\
& 37.0 & 13 & &
\end{tabular}

${ }^{a}$ Values deduced from experiments on the pure substances. ${ }^{b}$ Values deduced from experiments on the binary heterogeneous mixtures.

present study ( $\sim 223{ }^{\circ} \mathrm{C}$ for Tan's work) is not related to the degradation of VC since it is not obtained when the pan used is half-opened.

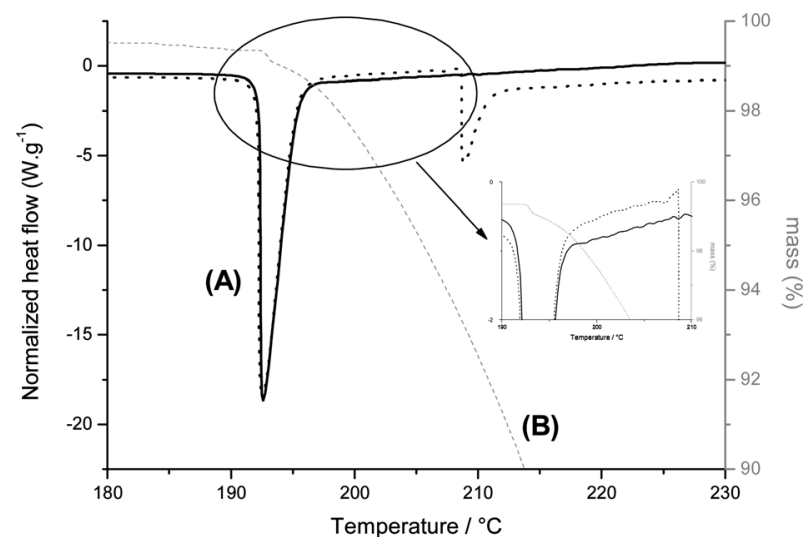

Fig. 4 Thermograms obtained for $1.75 \mathrm{mg}$ of vitamin $\mathrm{C}$ heated from 25 to $250^{\circ} \mathrm{C}$, scan rate: $8^{\circ} \mathrm{C} \mathrm{min}^{-1}$. (A) The DSC pan was either hermetically sealed (dotted black line) or half opened (solid black line). The corresponding TGA curve is represented in grey dashed line $(B)$. The inset shows a zoom of the DSC baseline during mass change of the sample observed by TGA.

Therefore, we propose that this endothermic signal corresponds to the explosion of the DSC pan caused by the increase of the pressure inside the capsule due to gaseous degradation product. Complementarily to the DSC experiments, thermogravimetric analyses were carried out under half-opened conditions (Fig. 4, curve B). The result confirms that the degradation process occurs at the same time as VC melting (mass loss: $\sim 1 \%$ ). Taken together, the thermal experiment data obtained here allow us to conclude that the enthalpy value proposed by Tan was not determined for a melting process (i.e. an equilibrium established between solid and liquid vitamin C). Indeed, in such a case, working in a closed pan leads to establishing a heterogeneous equilibrium between several components including pure VC and its degraded compounds, which can be either solid, liquid and/or gaseous. However, the VC $\Delta_{\text {fus }} H$ obtained by $\operatorname{Tan}^{10}\left(45.6 \mathrm{~kJ} \mathrm{~mol}^{-1}\right)$ is closer to the one we obtained by extrapolation of the heating scan rate. Consequently, the VC melting enthalpy that has been obtained until now may not be tangible. Finding a way to prevent VC from degrading upon melting therefore becomes a challenge to have access to its real enthalpy of fusion.

\section{Heterogeneous association between vitamin $\mathrm{C}$ and stearic acid}

When solid-solid dispersions prepared by mixing $\mathrm{VC}$ and SA are heated, two endothermic peaks can be observed on the corresponding thermograms. Interestingly, the two signal positions are independent regarding mole fractions and scan rates (from 2 to $50{ }^{\circ} \mathrm{C} \mathrm{min}^{-1}$ ) as reported in Fig. 5. The lowest temperature signal and the highest one correspond to the SA and VC melting processes, respectively. Such thermal behavior manifests itself for heterogeneous systems, i.e. systems in which each component retains its own chemical property. The VC-SA system is thus heterogeneous since no chemical interaction or chemical reaction occurs between SA and VC, whatever the composition.

This result was confirmed by X-ray diffraction patterns obtained as a function of temperature and molar composition. 
A

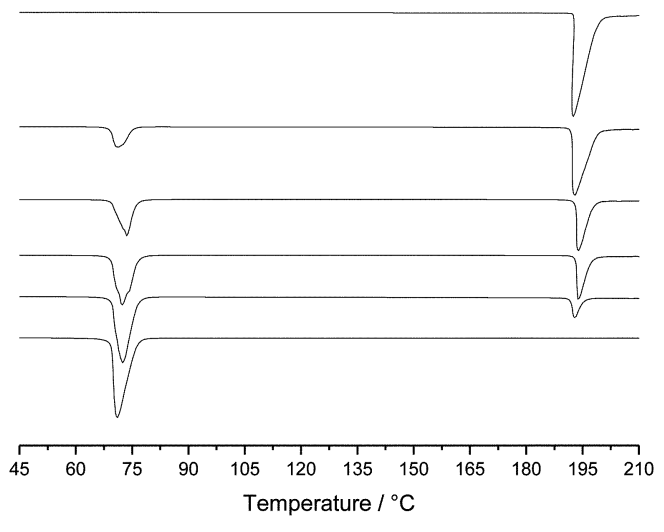

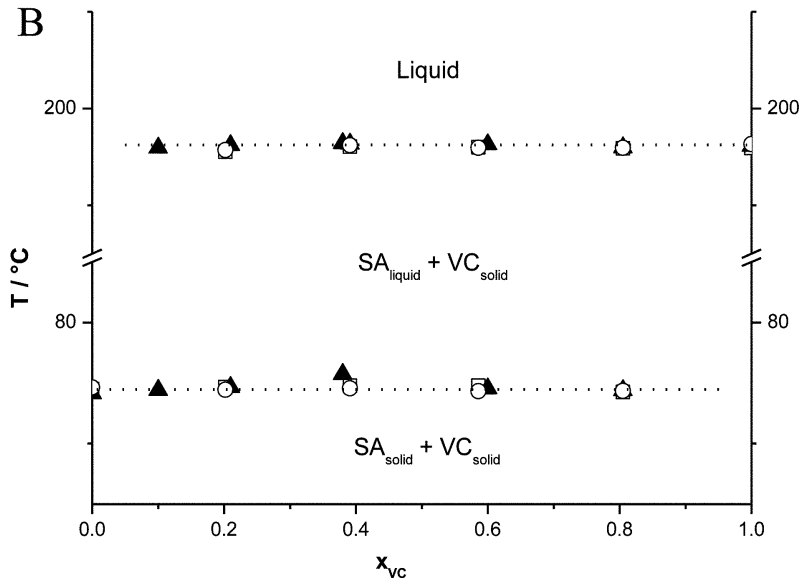

Fig. 5 (A) Selected weight normalized DSC thermograms obtained for stearic acid vitamin C mixtures at $20^{\circ} \mathrm{C} \mathrm{min}^{-1}$. VC mole fractions: $0.0,0.2,0.4,0.6,0.8$, and 1.0 from the bottom to the top curve. The thermograms were shifted for clarity. (B) The resulting binary phase diagram. Scan rates: $(\square) 5,(\boldsymbol{\Lambda}) 10$, and $(O) 20{ }^{\circ} \mathrm{C}$ min ${ }^{-1}$.
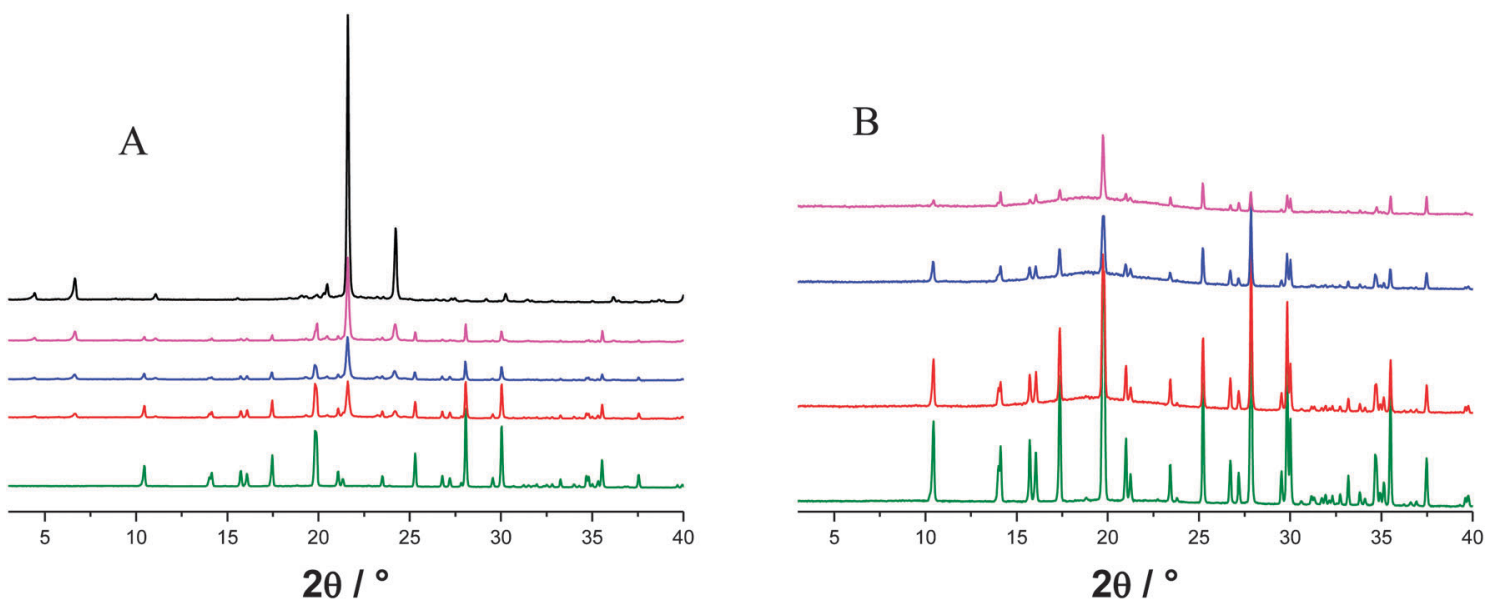

Fig. $6 \mathrm{X}$ ray powder diffraction patterns measured at (A) $22^{\circ} \mathrm{C}$, and (B) $100{ }^{\circ} \mathrm{C}$. VC mole fraction from bottom to top: $1.00,0.75,0.50,0.25,0.00 . S A$ being liquid at $100{ }^{\circ} \mathrm{C}$, no $\mathrm{X}$ ray powder diffraction pattern is presented in panel $\mathrm{B}$ for the $0.00 \mathrm{VC}$ mole fraction.

Fig. 6 presents some patterns recorded at 20 and $100{ }^{\circ} \mathrm{C}$, respectively. On these figures, one can see that the diffraction patterns of the mixtures correspond to the superposition of the patterns of the pure substances, with no supplementary peaks and with the intensities of the Bragg peaks proportional to the relative quantity of the pure substances present in the mixture. It must be noted that SA is in the liquid state at $100{ }^{\circ} \mathrm{C}$, and that may account for the broad diffusion peak for $15^{\circ} \leq 2 \theta \leq 25^{\circ}$ (Fig. 6B).

The thermograms obtained for the binary mixtures between VC and SA do not show any signs of degradation during the melting of VC. This result was also visually confirmed after the heating runs (Fig. 7).

As seen in Fig. 7, the degradants of vitamin $\mathrm{C}$ are pulled out of the pan after the melting, which is not the case when stearic acid is mixed to vitamin C. The same tendency was observed regardless of the mixture composition. Moreover, the melting temperatures of VC, obtained at different scan rates and for different mole fractions, are the same. The mean VC melting temperature value of $192.2 \pm 0.5{ }^{\circ} \mathrm{C}$, thus determined, is close
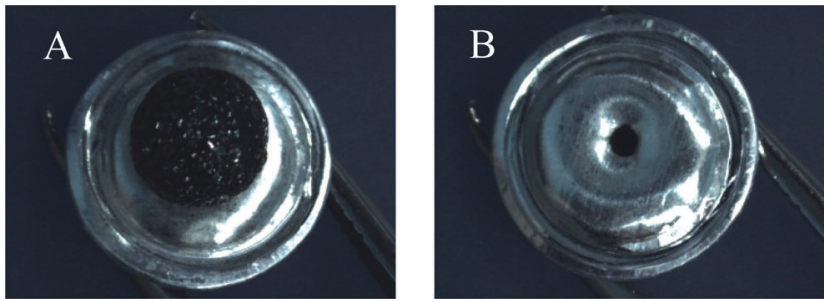

Fig. 7 Photos of the DSC pans taken after the heating run for pure VC (A) and the VC SA $(0.75 / 0.25)$ mixture (B).

to the one obtained from pure VC (Fig. 1D, Table 1), even though the corresponding error ranges do not overlap. As far as SA is concerned, its melting temperature $\left(69.2 \pm 0.7^{\circ} \mathrm{C}\right)$ found from the thermal study of the heterogeneous mixtures is also independent from scan rate and composition. This result aligns with the other data previously reported (Table 1).

From the DSC experiments carried out on the binary system, VC and SA melting enthalpies were determined as a function of the VC mole fraction (Fig. 8). As expected, the plot relative to SA 

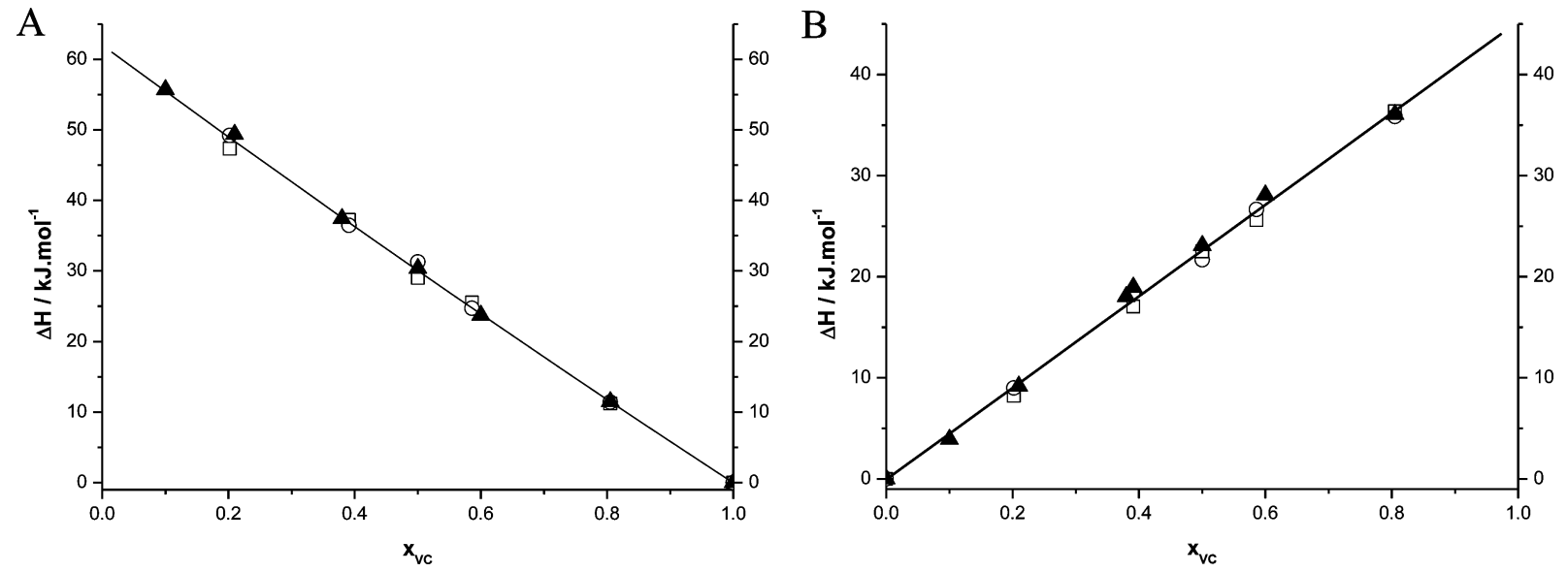

Fig. 8 Evolution of the melting enthalpy for stearic acid (A) and vitamin C (B) as a function of the mole fraction of vitamin C. Scan rate: ( $\square)$ 5, ( $\mathbf{\Delta})$ 10, and (O) $20{ }^{\circ} \mathrm{C} \mathrm{min}^{-1}$.

is linear with $x$ (Fig. 8A) and the extrapolation at $x=0$ gives access to a melting enthalpy mean value for pure stearic acid $61.1 \pm 0.4 \mathrm{~kJ} \mathrm{~mol}^{-1}$ (Table 1). Interestingly, the melting enthalpy of $\mathrm{VC}$, as a function of the VC mole fraction, also increases linearly (Fig. 8B). The value tends, for $x=1$, to a melting enthalpy for pure vitamin $\mathrm{C}$ equal to $45.6 \pm 0.8 \mathrm{~kJ} \mathrm{~mol}^{-1}$ (Table 1).

Because (i) a linear $\left(\Delta_{\text {fus }} H\right.$ vs. $\left.x\right)$-plot is obtained for the VC-SA mixtures, (ii) the VC melting temperature is constant whatever the heating rate, (iii) the DSC signals and pans show a few VC degradation traces, the melting enthalpy of vitamin C can be estimated by the cross section between the $\left(\Delta_{\text {fus }} H v s . x\right)$-plot and the $(x=1)$-axis.

\section{Thermal stability of vitamin $\mathrm{C}$ under isothermal conditions}

To confirm the assumption that SA prevents VC from degradation, or at least that the degradation is minimized, the thermal stability of VC was apprehended via different heating times under isothermal conditions. The resulting products were analyzed by HPLC in order to determine the fraction of nondegraded $\mathrm{VC}$ as a function of the annealing time.

To compare the possible effect of SA on the stability of VC regarding the thermal conditions, the experiments were carried out with pure VC as well as with mixtures of VC and SA. The ascorbic acid concentration in solution as well as the degradation products appearing upon heating were detected by an HPLC method using an internal calibration. Riboflavin was chosen as the internal standard because, for the HPLC method, the adopted experimental conditions allow separating riboflavin and VC. In addition, DSC experiments have proved that riboflavin does not interact either with VC or with SA. Indeed, no change in the melting temperatures and enthalpies for SA and VC was found for each compound when VC was mixed with riboflavin and/or SA. The DSC analysis of the ternary mixtures between SA, VC and riboflavin leads to the same conclusion, i.e. that no specific interaction exists between the three components because the melting point of $\mathrm{VC}$ is unchanged even in the presence of riboflavin and stearic acid (results not shown).

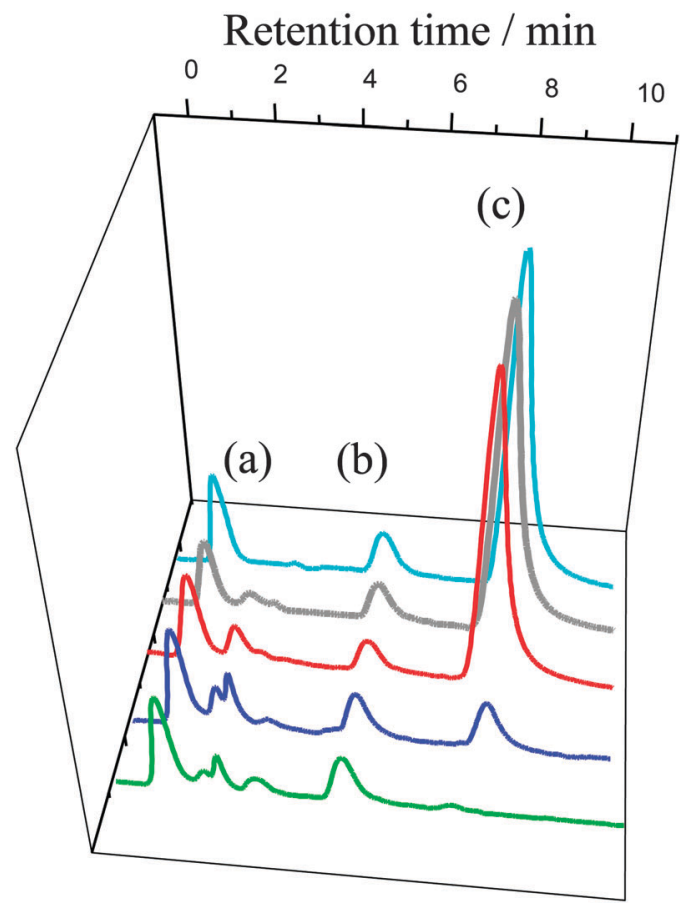

Fig. 9 Chromatograms obtained for pure vitamin $\mathrm{C}$ heated at $195^{\circ} \mathrm{C}$. Annealing time in $\min$ (from top to bottom): $0,1,1.5,20$, and 30. Signal label: degradants (a), riboflavin (b), and pure vitamin C (c).

In Fig. 9, are reported the chromatograms obtained after solubilization of pure VC heated at $195{ }^{\circ} \mathrm{C}$ for $1 \mathrm{~min}, 1.5 \mathrm{~min}$, $20 \mathrm{~min}$ and $30 \mathrm{~min}$. Interestingly, the peak intensity of $\mathrm{VC}$ decreased with time, highlighting the emergence of degradation products. The latter have lower retention times than VC. As for riboflavin, the peak intensity remained unchanged with time, indicating that this substance was not co-eluted with the degradation products.

The degradation products of vitamin $\mathrm{C}$ have already been identified by Yuan and $C h e{ }^{19}$ The authors proposed an example of the degradation pathway, as summarized in Fig. 10. In an acid environment, they showed that the degradation of 


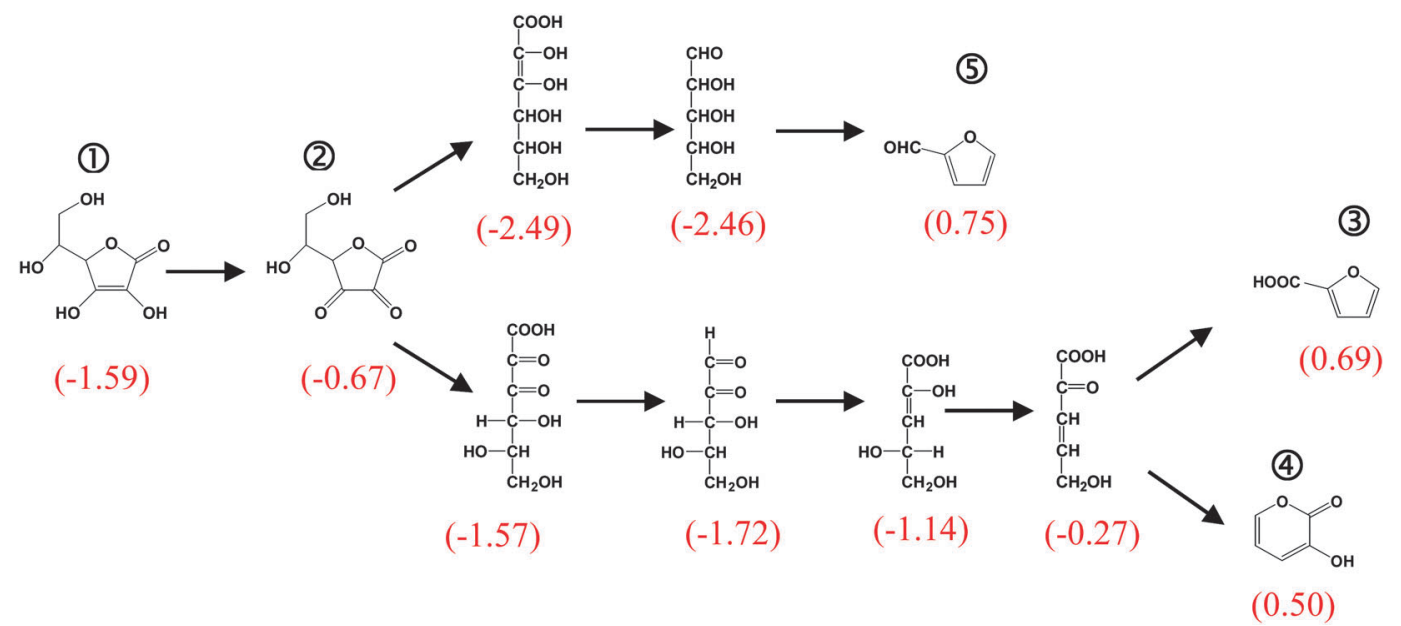

Fig. 10 Degradation products of ascorbic acid according to Yuan and Chen ${ }^{19}$ (1): ascorbic acid, (2): dehydroascorbic acid, (3): 2 furoic acid, (4): 3 hydroxy 2 pyrone, (5): furfural. The values of $\log P_{\text {oct/water }}$ are reported in brackets.

ascorbic acid was carried out simultaneously by two reaction pathways:

- under aerobic conditions, ascorbic acid (1) was converted to 2-furoic acid (3) and 3-hydroxy-2-pyrone (4) via dehydroascorbic acid (2),

- under anaerobic conditions, ascorbic acid degraded to furfural (5).

The $\log P_{\text {oct } / \text { water }}$ value, for each degradation product, indicates the hydrophobic behavior of the degradation products. The higher the value is, the higher the hydrophobicity of the molecule is. It comes out that the degradation products (from (2) to (5)) are more hydrophobic than ascorbic acid because their $\log P_{\text {oct/water }}$ value is higher than the $\mathrm{VC}$ one, from +0.5 to +0.75 , versus -1.59 for ascorbic acid. In the case of HILIC chromatography, the retention is mainly caused by partitioning the analyte between a water-enriched layer immobilized at the stationary phase surface and the relatively hydrophobic mobile phase. The retention mechanism in HILIC is, however, likely to be complex, and the partition mechanism originally envisaged may occur together with hydrophilic interaction, adsorption and ion exchange. ${ }^{20,21}$ Hence, the more hydrophobic the compounds are, the less retained they are by the stationary phase, i.e. the lower the retention time is, which is the case of the degradation products of ascorbic acid. At the $\mathrm{pH}$ of the mobile phase $(\mathrm{pH}=3.5)$, ascorbic acid $\left(\mathrm{pK}_{\mathrm{a}_{1}}=4.3, \mathrm{p} K_{\mathrm{a}_{2}}=11.7\right)$ is partially anionic in contrast to its degradation products. This explains why VC, unlike its degradation products, has been partially retained by the HILIC stationary phase due to ionic interactions.

The percentages of non-degraded VC, determined from integration of the peaks presented in Fig. 9, are reported in Fig. 11, as a function of time, for pure VC and for VC mixed with SA. As it can be seen, when VC is mixed with SA, the rate of degradation is significantly lower. Then, when VC is heated for $30 \mathrm{~min}$ at $195^{\circ} \mathrm{C}$, non-degraded VC is no longer present whereas about $80 \%$ of pure VC is still present in the mixture with SA.

From this graph one may say that the mixture of VC with SA improves the thermal stability of VC since the degradation is

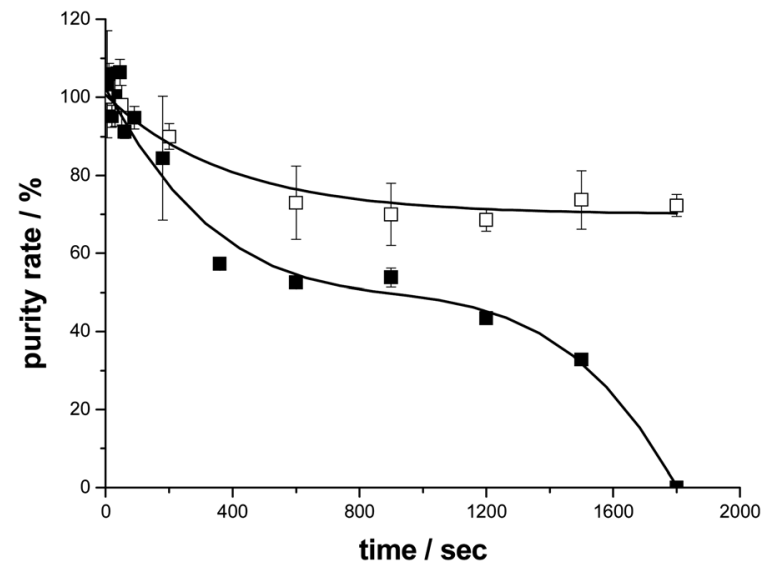

Fig. 11 Percentage of non degraded vitamin $C$ as a function of annealing time at $195{ }^{\circ} \mathrm{C}$ for pure vitamin $\mathrm{C}$ (filled squares), and vitamin $\mathrm{C}$ stearic acid mixtures (empty squares)

lower at a given annealing time and temperature. Consequently, this result justifies that the melting values of VC (temperature and enthalpy) may be deduced from the range of heating rates used in this study, when the vitamin is mixed with SA.

\section{Conclusion}

The originality of the system formed by vitamin $\mathrm{C}$ and stearic acid as an excipient lies in the fact that, whatever the mole fraction between both components, complete immiscibility in the solid state as well as between liquid SA and solid VC, is encountered. Such a system is also called a heterogeneous system since each compound conserves its own properties. Thus, upon heating, each component melts as a single phase and reversibly, upon cooling, each component recrystallizes with no influence from the other component. Furthermore, since SA melts without degradation before VC, the excipient here plays the role of a protective agent in the sense that the liquid surrounds the VC powder. As a result, the melting properties 
of VC could have been measured and compared to the literature data. Furthermore, the extrapolated data obtained from the binary system were compared to the data obtained with pure VC. It is clear that vitamin $\mathrm{C}$, heated at high scan rates or mixed to stearic acid, presents the same melting data. Assuming a melting-degradation process for pure VC, one may conclude that, at high scan rates, pure VC degradation is strongly attenuated. Under such conditions, only the melting of vitamin takes place, with any significant degradation. Therefore, the extrapolated values can be attributed to vitamin C melting data.

The thermal analysis - chromatography complementary methods carried out in this study allowed us to propose the temperature and enthalpy of melting for vitamin $\mathrm{C}$ using the specific property of the association between SA and VC. The formulation of such heterogeneous systems can be useful for many applications in the pharmaceutical field where chemical interactions and/or degradation are often harmful. This is true for substances such as spironolactone ${ }^{5}$ or prednisolone. ${ }^{2,23}$ Overall, our findings support the interest of the complementarity between thermal analyses and chromatographic assays in order to determine thermodynamic quantities, which are impossible to obtain by using thermal methods only.

\section{Acknowledgements}

We thank Ms B. Mohamed, an MSc student and intern in our laboratory for her contribution to this work, Ms G. ArnaudVincent and M. P. Bardy for fruitful discussions and advice on the manuscript.

\section{Notes and references}

1 L. Zhang, S. Lerner, W. V. Rustrum and G. A. Hofmann, Bioelectrochemistry, 1999, 48, 453.

2 R. E. Fitzpatrick and E. F. Rostan, Dermatol. Surg., 2002, 28, 231.

3 G. Spigno, D. M. de Faveri and P. Perego, Ind. Aliment., 1999, 38, 538.
4 V. Wegmann and K. Pommerenke, GIT Labor-Fachz., 2000, 44, 422.

5 A. Marini, V. Berbenni, G. Bruni, A. Maggioni, A. Orlandi and M. Villa, Thermochim. Acta, 2001, 374, 171.

6 P. Morganti, J. Appl. Cosmetol., 1994, 12, 25.

7 N. H. Shah, C. I. Patel, M. H. Infeld, R. J. Margolis, A. M. Railkar and A. W. Malick, Drug Dev. Ind. Pharm., 1996, 22, 1097.

8 Y. Corvis, P. Negrier and P. Espeau, J. Pharm. Sci., 2012, 100, 5235.

9 T. Kehl and G. van der Plaats, US Patent, 5.033.866, 1991.

10 Y. Tan, Wuxi Qinggong Daxue Xuebao, 2003, 22, 102.

11 K. A. Park, H. J. Lee and I. K. Hong, J. Ind. Eng. Chem., 2010, 16, 490 .

12 X. Tian, D. Tian, Z. Wang and F. Mo, J. Appl. Polym. Sci., 2009, 114, 2986.

13 L. Kofler and H. Sitte, Monatsh. Chem., 1950, 81, 619.

14 K. Klimova and J. leitner, Thermochim. Acta, 2012, 550, 59.

15 P. Mura, G. P. Bettinetti, M. T. Fauci, A. Manderioli and P. L. Parrini, Thermochim. Acta, 1998, 321, 59.

16 R. C. F. Schaake, J. C. van Miltenburg and C. G. de Kruif, J. Chem. Thermodyn., 1982, 14, 771.

17 K. Sato, N. Yoshimoto, M. Suzuki, M. Kobayashi and F. Kaneko, J. Phys. Chem., 1990, 94, 3180.

18 E. Moreno, R. Cordobilla, T. Calvet, M. A. Cuevas-Diarte, G. Gbabode, P. Négrier, D. Mondieig and H. A. J. Oonk, New J. Chem., 2007, 31, 947.

19 J. P. Yuan and F. Chen, J. Agric. Food Chem., 1998, 46, 5078.

20 D. V. McCalley, J. Chromatogr., A, 2007, 1171, 46; D. V. McCalley, J. Chromatogr., A, 2008, 1193, 85.

21 A. J. Alpert, J. Chromatogr., 1990, 499, 177.

22 V. Suitchmezian, I. Jess, J. Sehnert, L. Seyfarth, J. Senker and C. Näther, Cryst. Growth Des., 2008, 8, 98.

23 G. De Maury, A. Chauvet, A. Terol and J. Masse, Thermochim. Acta, 1986, 97, 127. 